\title{
Activity of Cinnamomum osmophloeum leaf essential oil against Anopheles gambiae s.s
}

\author{
France P Mdoe', Sen-Sung Cheng ${ }^{2}$, Shandala Msangi ${ }^{3}$, Gamba Nkwengulila', Shang-Tzen Chang ${ }^{4}$ \\ and Eliningaya J Kweka ${ }^{3,5^{*}}$
}

\begin{abstract}
Background: The increasing status of insecticide resistant mosquitoes in sub-Saharan Africa is a threatening alert to the existing control efforts. All sibling species of An. gambiae complex have evolved insecticide resistance in wild populations for different approved classes of the insecticides currently in use in the field. An alternative compound for vector control is absolutely urgently needed. In this study, the larvicidal activity and chemical composition of the Cinnamomum osmophloeum leaf essential oils were investigated.
\end{abstract}

Methods: C. osmophloeum leaf essential oils were extracted by hydrodistillation in a Clevenger-type apparatus for 6 hours, and their chemical compositions identified using GC-MS. These oils were evaluated against An. gambiae s.s. in both laboratory and semi-field situations. The WHO test procedures for monitoring larvicidal efficacy in malaria vectors were used.

Results: The composition of C. osmophloeum leaf essential oil has been found to have 11 active compounds. The most abundant compound was trans-cinnamaldehyde (70.20\%) and the least abundant was caryophyllene oxide (0.08\%). The larvicidal activity was found to be dosage and time dependant both in laboratory and semi-field environments with mortality ranging from $0 \%$ to $100 \%$. The $L C_{50}$ value was found to vary from 22.18 to $58.15 \mu \mathrm{g} / \mathrm{ml}$ in the laboratory while in semi-field environments it was 11.91 to $63.63 \mu \mathrm{g} / \mathrm{ml}$. The $L C_{90}$ value was found to range between 57.71 to $91.54 \mu \mathrm{g} / \mathrm{ml}$ in the laboratory while in semi-field environments was 52.07 to $173.77 \mu \mathrm{g} / \mathrm{ml}$. Mortality ranged from 13\% to $100 \%$ in the laboratory while in semi-field environments it ranged between $43 \%$ to $100 \%$ within mortality recording time intervals of $12,24,48$, and 72 hours.

Conclusions: The larvicidal activity shown by C. osmophloeum leaf essential oil is a promising alternative to existing larvicides or to be incorporated in integrated larval source management compounds for An. gambiae s.s control. The efficacy observed in this study is attributed to both major and minor compounds of the essential oils.

\section{Background}

Malaria vector species insecticide resistance status has been a drawback from the existing control tools. Insecticide resistance has been reported for the main malaria vectors, An. gambiae s.s, An. arabiensis and An. funestus [1-5]. Mosquitoes play a major role in the transmission of public health diseases such as malaria, dengue fever and arboviruses diseases which causes high mortality and morbidity for human populations globally $[6,7]$. The

\footnotetext{
* Correspondence: pat.kweka@gmail.com

${ }^{3}$ Division of Livestock and Human Diseases Vector Control, Tropical Pesticides Research Institute, Ngaramtoni, Off Nairobi Road, PO Box 3024, Arusha,

Tanzania

${ }^{5}$ Department of Medical Parasitology and Entomology, Catholic University of Health and Allied Sciences, PO Box 1464, Mwanza, Tanzania

Full list of author information is available at the end of the article
}

classes of insecticides which are used for indoor residual spray (i.e., organophosphates, carbamate, organochlorides, and pyrethroids) for net treatment and for larvicides (carbamates) have been reported to have reduced mortality $[1-3,5,8]$. Currently there is a need for the new class of insecticide molecules which will be incorporated in integrated vector management to reduce the insecticide resistant problem. In recent years, there is renewed interest on the plant kingdom to produce bio-pesticides. In malaria endemic areas several plant species have been used to extract essential oils for different insecticidal activities be it for crop pests control [8-10] or animal and human medicine and biting pests control [11].

Arthropod control plant based insecticides have been used since ancient times [12,13]. Malaria vector control 
has received serious attention in control using plant material. Plant materials have been used as repellents by burning or hanging whole plants indoors [11,14-16] by having selected repellent plants around houses [16]. In advancement of technology plant essential oil extraction has been through distillation and used as plant repellents against mosquito and other biting midges $[17,18]$. In invention of GC-MS it has been possible to separate individual components of plant essential oils and test their repellent, larvicidal, ovicidal or adulticidal efficacy for each single compound [19].

Family Lauraceae consists of trees of economic importance. The genus Cinnamomum comprises of 250 species distributed in Asia and Australlia [20]. C. osmophloeum Kaneh has been of great interest in research due to its chemical constituents being similar to those of $C$. cassia bark oil [21]. Cinnamon is an endangered tree that grows in Taiwan at an elevation of 400 to $1500 \mathrm{~m}$ in natural hardwood forest. In previous research findings, essential oils extracted from leaves of C. osmophloeum have antiviral, antifungal, and antibacterial activities [22,23]. Also the essential oil from the leaves of C. osmophloeum has been found to have the strongest mosquito larvicidal activities against different mosquito species [24,25]. It is of interest to understand if the essential oil from leaves of C. osmophloeum possesses action against Afrotropical malaria vectors An. gambiae s.s. Therefore, it was the aim of this study to assess the chemical composition of essential oils from leaves of C. osmophloeum and its larvicidal activity against $A n$. gambiae s.s mosquito larvae.

\section{Methods}

\section{Plant material and essential oil extraction}

Mature leaves of C. osmophloeum were collected in July, 2008 from the Da-Pin-Ting of the Taiwan Sugar Farm, the location is situated in Nantou County of central Taiwan. The species were identified by Mr. Yen-Ray Hsu of the Taiwan Forestry Research Institute and the voucher specimen (COL027) was deposited at the laboratory of wood chemistry, School of Forestry and Resource Conservation, National Taiwan University. The sample (200 g each), in triplicate, was subjected to hydrodistillation in a Clevenger-type apparatus for 6 hours [26], followed by determination of oil contents. The leaf essential oil obtained was separated from the aqueous phase and stored in airtight containers at $4^{\circ} \mathrm{C}$ prior to further analysis.

\section{GC-MS analysis}

Analyses of volatile constituents were determined using a Polaris Q Ion Trap GC/FID/MS ${ }^{\mathrm{n}}$ system (Thermo, USA), equipped with a fused silica column $(30 \mathrm{~mm} \times 0.25 \mathrm{~mm}$ i.d.) and coated with $5 \%$ phenyl-methylpolysiloxane using a DB-5 ms $(\mathrm{df}=0.25 \mu \mathrm{m})$ (Agilent J \& W Scientific). The temperature program used for the analysis was as follows: initial temperature at $80^{\circ} \mathrm{C}$, held for $1 \mathrm{~min}$, ramped at $4{ }^{\circ} \mathrm{C} / \mathrm{min}$ to $200^{\circ} \mathrm{C}$ and held for $5 \mathrm{~min}$. Helium was the carrier gas at $1.0 \mathrm{ml} / \mathrm{min}$; the sample $(1.0 \mu \mathrm{l}$, $1 / 100, v / v$, in ethyl acetate) was injected in the split mode (1:10). The mass spectrometer was equipped with a Polaris Q mass selective detector in electron impact (EI) ionization mode $(70 \mathrm{eV})$. The ion source temperature and the injector temperature were set at $230^{\circ} \mathrm{C}$ and $270^{\circ} \mathrm{C}$, respectively. The sector mass analyzer was set to scan from 50 to $450 \mathrm{amu}$ every $0.5 \mathrm{~s}$. The Kovats retention indices were calculated for all volatile constituents using a homologous series of $n$-alkanes $\mathrm{C}_{9}-\mathrm{C}_{17}$ on DB- $5 \mathrm{~ms}$ column. Quantification was performed using percentage peak area calculations and the identification of individual components was done using the Wiley/NBS Registry of Mass Spectral Database and NIST MS Search 2.0, the literature [27], and several authentic reference compounds. The relative concentration of each compound in essential oil was quantified according to the peak area integrated by the analysis program.

\section{Larval rearing for experiments}

Eggs laid were incubated for 48 hours in an insectary incubator at a temperature of $27 \pm 2^{\circ} \mathrm{C}$ and a relative humidity of $78 \pm 2 \%$. Immediately after 48 hours of incubation filter papers were washed on a rearing pan. The first instar larvae were provided with yeast. Second instars onwards were fed with tetramin fish food 0.003 gm per larvae. Third instar larvae were used for experiments in evaluating the larvicidal action of the leaf essential oil of C. osmophloeum.

\section{Larval bioassays in the laboratory}

A number of cups (diameter $10 \mathrm{~cm}$, depth $10 \mathrm{~cm}$ with capacity of $100 \mathrm{mls}$ ) were prepared in six replicates for each treatment dosage with a control, and each replicate received 20 third instar larvae, as well as control. One control contained normal laboratory larval rearing water while the other was an aqueous solution of $0.50 \%$ of dimethyl sulfoxide (DMSO) that was used as dispersing medium for the essential oil and exposure to larvae for treatment. The number of serial dilutions made for dosages effective enough to cause mortality were as described in WHO larval bioassay protocol [28]. The test was performed by serial dilutions, 200, 100, 50, 25, and $12.5 \mu \mathrm{g} / \mathrm{ml}$, using normal laboratory larval rearing water. Larvae were not provided with food and mortality recordings were taken at $12,24,48$, and 72 hours for both treatments and control. The dead and moribund larvae were all considered as dead.

\section{Larval bioassay in the semi-field}

Semi-field environment structures used in this study were similar to those described in previous studies [29]. 
Table 1 Constituents of leaf essential oil from Cinnamomum osmophloeum

\begin{tabular}{cclcc}
\hline NO & $\mathbf{R T}^{\mathbf{a}}$ & Compounds & Area, $\%$ & $\mathbf{K l}^{\mathbf{b}}$ \\
\hline 1 & 6.45 & Benzaldehyde & 0.45 & 965 \\
2 & 12.61 & Benzenepropanal & 0.82 & 1164 \\
3 & 13.05 & 2-Methyl benzofuran & 0.14 & 1176 \\
4 & 13.83 & 4-Allylanisole & 0.17 & 1197 \\
5 & 14.51 & cis-Cinnamaldehyde & 0.33 & 1219 \\
6 & 16.31 & trans-Cinnamaldehyde & 70.20 & 1273 \\
7 & 16.74 & L-Bornyl acetate & 0.48 & 1285 \\
8 & 18.90 & Eugenol & 0.10 & 1351 \\
9 & 21.15 & trans- $\beta$-Caryophyllene & 0.18 & 1419 \\
10 & 21.92 & trans-Cinnamyl acetate & 27.05 & 1444 \\
11 & 26.09 & Caryophyllene oxide & 0.08 & 1580 \\
\multicolumn{7}{l}{ Total identified } & & 100.00 & \\
\hline
\end{tabular}

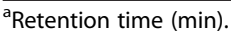

${ }^{b}$ Kovats index relative to $n$-alkanes $\left(C_{9}-C_{17}\right)$ on a DB- 5 ms column.

The semi-field evaluation protocol was adopted from the WHO protocol [28]. The same dosages used in the laboratory were evaluated in the semi-field. A series of cups (with diameter of $10 \mathrm{~cm}$ and depth $10 \mathrm{~cm}$, with capacity of $100 \mathrm{mls}$ ) were prepared in six replicates for each control and treatment, and each replicate received 20 third instar larvae. Controls, one had normal laboratory larval rearing water and the other had an aqueous solution of $0.50 \%$ of DMSO that was used as dispersing medium for the essential oil and exposure of larvae to treatment. Other procedures were performed similar to the larval bioassays in the laboratory.

\section{Statistical analysis}

The Scheffe multiple comparison procedure of SAS statistical program was used to analyse mosquito larvicidal activity of $C$. osmophloeum leaf essential oil $(P<0.05)$. All results were obtained from four independent experiments and expressed as mean \pm SD.

Mortality was recorded after 12, 24, 48, and $72 \mathrm{~h}$ of exposure, during which no food was given to the larvae. Percent mortality was corrected for control mortality using Abbott's formula [30], and the results were plotted on $\log$ /probability paper using the method developed by Finney [31]. Toxicity and activity were reported as $\mathrm{LC}_{50}$ and $\mathrm{LC}_{90}$, representing the concentration in $\mu \mathrm{g} / \mathrm{ml}$ that caused 50 and $90 \%$ larval mortality, respectively, in 12 , 24,48 , and 72 hours.

\section{Results \\ Chemical composition}

In GC-MS chemical analysis of the C. osmophloeum leaf essential oils have found 11 compounds with trans-cinnamaldehyde as the highest abundant compound with $70.20 \%$ and caryophyllene oxide found to have the least amount of $0.8 \%$. The other 9 compounds occurred in different composition percentages (Table 1). The yield of essential oils from C. osmophloeum leaves was $44.47 \pm 0.68$ $\mathrm{mls} / \mathrm{Kg}$ and composition of $2.82 \pm 0.09 \%$ (w/w).

\section{Larval bioassays in the laboratory}

From the range of doses used, the mortality effect from 12 to 72 hours of observation was found to be dosage dependant. In each mortality observation time, the lowest dosage had lowest mortality while the highest dosage had the highest mortality (Table 2). After 72 hours the mean percentage mortality ranged from 13 to $100 \%$ for An. gambiae s.s. larvae (Table 2). The interval observations $(12,24,48$, and 72 hours) in each concentration among laboratory experiments had mortality responses that varied with time (Table 2). The dosage of essential oil required to kill $50 \%\left(\mathrm{LC}_{50}\right)$ and $90 \%\left(\mathrm{LC}_{90}\right)$ of the larvae varied with time of exposure (Table 3 ).

\section{Larval bioassay in the semi-field}

The mortality trends observed in the semi field experiments were similar to that in laboratory assays for mortality been dosage dependance in every observation time. Mortality rate was higher in semi-field environments compared to those observed in the laboratory, it ranged between $43 \%$ in $12.5 \mu \mathrm{g} / \mathrm{ml}$ to $100 \%$ in $200 \mu \mathrm{g} / \mathrm{ml}$ (Table 4). The dosage of essential oil required to kill $50 \%$ $\left(\mathrm{LC}_{50}\right)$ and $90 \%\left(\mathrm{LC}_{90}\right)$ of the larvae varied with time of exposure, it was observed to be higher than in the laboratory (Table 3) (12, 24, 48, and 72 hours) each concentration

Table 2 Larvicidal effect of Cinnamomum osmophloeum leaf essential oil against Anopheles gambiae s.s in different time intervals and concentrations in the laboratory

\begin{tabular}{|c|c|c|c|c|c|c|c|c|c|}
\hline Time & 200 & 100 & 50 & 25 & 12.5 & Equation & $\mathrm{R}^{2}$ & $\mathrm{LC}_{50}$ & $\mathrm{LC}_{90}$ \\
\hline $\mathrm{Oh}$ & 0 & 0 & 0 & 0 & 0 & & & & \\
\hline $12 \mathrm{~h}$ & 100 & 100 & 43 & 3 & 0 & $y=1.1979 x-19.652$ & 0.9873 & 58.15 & 91.54 \\
\hline $24 \mathrm{~h}$ & 100 & 100 & 80 & 19 & 1 & $y=51.648 \operatorname{Ln}(x)-134.15$ & 0.9477 & 35.36 & 76.70 \\
\hline $48 \mathrm{~h}$ & 100 & 100 & 95 & 44 & 9 & $y=46.743 \operatorname{Ln}(x)-104.66$ & 0.9264 & 27.35 & 64.36 \\
\hline $72 \mathrm{~h}$ & 100 & 100 & 97 & 68 & 13 & $y=41.838 \operatorname{Ln}(x)-79.672$ & 0.8615 & 22.18 & 57.71 \\
\hline
\end{tabular}


Table $3 L C_{50}$ and $L C_{90}$ values of leaf essential oil from Cinnamomum osmophloeum in laboratory and semi-field environments against Anopheles gambiae s.s

\begin{tabular}{cccccc}
\hline \multirow{2}{*}{ Time } & \multicolumn{2}{c}{$\mathrm{LC}_{\mathbf{5 0}}(\boldsymbol{\mu g} / \mathrm{ml})$} & & \multicolumn{2}{c}{$\mathrm{LC}_{\mathbf{9 0}}(\boldsymbol{\mu g} / \mathrm{ml})$} \\
\cline { 2 - 3 } \cline { 6 - 6 } \cline { 5 - 6 } & Laboratory & Semi-field & & Laboratory & Semi-field \\
\hline $24 \mathrm{~h}$ & 58.15 & 63.63 & & 91.54 & 173.77 \\
$48 \mathrm{~h}$ & 35.36 & 42.46 & & 76.70 & 131.07 \\
$72 \mathrm{~h}$ & 27.35 & 22.37 & & 64.36 & 94.08 \\
\hline
\end{tabular}

among semi-field experiments had mortality responses that varied with time (Table 3).

\section{Discussion}

The findings of this study have shown that the essential oils of C. osmophloeum leaves have potential in inducing larval mortality both in semi-field and in laboratory environments. The mortality in the laboratory ranged from 13 to $100 \%$ while for semi-field ranged from 43 to $100 \%$ for dosages ranging from $12.5 \mu \mathrm{g} / \mathrm{ml}$ to $200 \mu \mathrm{g} / \mathrm{ml} \mathrm{re-}$ spectively. The mortality increase was observed in semifield trials, this might be attributed with the breakdown of compounds into secondary metabolites, which are more efficient when exposed to sunlight. The same trend was revealed when the plant essential oils were evaluated in a semi-field environment where experiments are exposed to sunlight and more mortality was observed than in the laboratory [29]. In other experiments mortality was observed to decrease when experimental material was exposed to sunlight in semi-field environments [29]. This shows that, the plant phyto-compounds should be assessed enough before exposed to sunlight for whether its secondary metabolites increase or decrease larval mortality. The larvicidal efficacy of the essential oils in both laboratory and semi-field experiments were shown to decrease with time as shown by $\mathrm{LC}_{50}$ and $\mathrm{LC}_{90}$ values in Table 3.

The mortality response caused by C. osmophloeum leaf essential oil to An. gambiae s.s larvae might have been influenced highly by trans-cinnamaldehyde and which occurred in higher proportion that others, but also, ciscinnamaldehyde might have a role in inducing mortality as well. In other experiments where the active compounds of C. osmophloeum leaf essential oil were evaluated singly, trans-cinnamaldehyde and cis-cinnamaldehyde induced the highest mortality against $C$. quinquefasciatus and A. subalbtus larvae at a minimal value of $\mathrm{LC}_{50}$ and $\mathrm{LC}_{90}$ [24]. $\mathrm{LC}_{50}$ and $\mathrm{LC}_{90}$ values observed in the current study for mortality of An. gambiae s.s larvae have been shown to be higher than in previous studies reported by Cheng and others [24], this might be attributed to hindrance factors from other active compounds in the essential oils evaluated. Evaluation of the active ingredient of the essential oils should be done singly to avoid miss matching of results with previous studies.

The screening of products from these leaf essential oils for larvicidal activity on An. gambiae s.s larval mosquitoes might lead to the most efficient compounds for the effective use in the larval sources treatment with residual effect against An.gambiae s.s larvae. The uses of synthetic insecticides for routine vector control have resulted in emergence of increase of resistance selection pressure among disease vectors [1-5]. This has increased the interest on searching for environmentally friendly, biodegradable, low-cost, and indigenous methods for vector control, which can be used without risk to none targeted organisms in communities [17,32]. The control of mosquito borne diseases can effectively achieve abatement which results in reduction of mosquitoes- human contact rates.

In this study, the laboratory and semi-field findings showed highest efficacy in mortality at lower dosages for the An. gambiae s.s. larvae (Tables 2 and 3). In the laboratory, mortality was dosage dependent, while in the semi-field, where other variables such as wind and sunlight were present, there was increased toxicity in lower dosages which increased mortality impact on larvae which was greater than the effect observed within laboratory experiments (Tables 2 and 3). The higher mortality in the lower dosages in the semi-field might be attributed to the degradation of compounds due to exposure to sunlight hence inducing more toxicity. The exposure of plant extracts to sunlight causes molecules to degrade to secondary metabolites which are thought to be the cause of the higher mortalities in semi-field experiments [29].

This essential oil may be of great value in complementing other compounds which are losing their efficacy

Table 4 Larvicidal effect of Cinnamomum osmophloeum leaf essential oil against Anopheles gambiae s.s in different time intervals and concentrations in semi-field environments

\begin{tabular}{cccccccccc}
\hline Time & $\mathbf{2 0 0}$ & $\mathbf{1 0 0}$ & $\mathbf{5 0}$ & $\mathbf{2 5}$ & $\mathbf{1 2 . 5}$ & Equation & $\mathbf{R}^{\mathbf{2}}$ & $\mathbf{L C}_{\mathbf{5 0}}$ & $\mathbf{L C}_{\mathbf{9 0}}$ \\
\hline $\mathrm{Oh}$ & 0 & 0 & 0 & 0 & 0 & & & & \\
$12 \mathrm{~h}$ & 100 & 80 & 18 & 4 & 0 & $y=39.818 \operatorname{Ln}(\mathrm{x})-115.37$ & 0.89 & 63.63 & 173.77 \\
$24 \mathrm{~h}$ & 100 & 92 & 48 & 32 & 7 & $y=35.49 \operatorname{Ln}(\mathrm{x})-83.039$ & 0.96 & 42.46 & 131.07 \\
$48 \mathrm{~h}$ & 100 & 99 & 81 & 58 & 24 & $y=27.844 \operatorname{Ln}(\mathrm{x})-36.526$ & 0.91 & 22.37 & 94.08 \\
$72 \mathrm{~h}$ & 100 & 100 & 96 & 79 & 43 & $y=27.123 \operatorname{Ln}(\mathrm{x})-17.204$ & 0.87 & 11.91 & 52.07 \\
\hline
\end{tabular}


against vectors, such as pyrethroids and others which are considered none-biodegradable and environmental pollutants such as 1,1,1-trichloro-2,2-bis( $p$-chlorophenyl) ethane (DDT) [33]. From other studies, some phytochemicals have acted as general toxicants against adult as well as larval stages of mosquitoes, while others interfere with growth and development (growth inhibitors) or with reproduction (chemosterilent) or produce olfactory stimuli acting as repellent or attractant [34]. There is renewed interest in the plant based resources for disease vector control bio-pesticides due to increased resistance for the existing selected insecticides in different vectors [1-5,7]. To date larval source management or control have shown a great impact when done alone or integrated with others tools such as indoor residual spray or insecticide treated nets, control impact has been observed in other areas [35]. This is because larval habitat treatment is more localized in time and space resulting in effective control as larvae cannot move from one habitat to another. In tropical countries, plants are known to possess larvicidal, ovicidal, and adulticidal activities [11,29].

The results of our current study in larvicidal properties of the essential oil of leaves of C. osmophloeum have created the necessity of investigating particular larvicidal activities of each chemical compound in this essential oil and drive their larvicidal activity potential. Further detailed study on the isolated active ingredients responsible for the larvicidal activity from these plant leaf essential oils may create opportunities for the development of an environmentally safe botanical insecticide for the control of mosquitoes at different stages of their life cycle.

Malarial transmission is much more difficult to control in Africa as compared to most other places because of a complex ecological system, it can be effectively achieved for targeting larval habitats. Larval source management strategies have proved to be infective in contributing to malaria eradication in other countries such as Brazil [36]. In that way, the leaf essential oil of C. osmophloeum a renowned natural source of larvicides could be used for the control of the African malaria vector mosquito, An. gambiae s.s.

\section{Conclusion}

The findings of this study have shown high mortality of An. gambiae s.s. third instar larvae caused by C. osmophloeum leaf essential oils was dosage and time dependant in both laboratory and semi-field trials. Further evaluations are ongoing for the efficacy of C. osmophloeum leaf essential oil adulticidal effects on wild populations of An. gambiae s.s.

\section{Competing interests}

Authors declare to have no competing interest in this work.

\section{Authors' contributions}

EJK, FPM, and STC conceived and designed the study. STC, SSC, and EJK carried out the data analysis and interpretation. FPM and SM did data collection and entry. FPM, EJK, and STC wrote the manuscript. EJK, GN, SSC, and STC revised the manuscript critically. All authors approved the final version for submission.

\section{Acknowledgements}

Authors are thankful to Adrian Massawe and Ester Lyatuu for larval rearing and experimental data collection assistance. TPRI is acknowledged for provision of her infrastructure to perform these experiments.

\section{Author details}

${ }^{1}$ Department of Zoology and Wildlife Conservation, College of Natural and Applied Sciences, University of Dar-es-salaam, PO Box 35165 Dar-es-salaam, Tanzania. ${ }^{2}$ Experimental Forest, National Taiwan University, Nan-Tou 557, Taiwan. ${ }^{3}$ Division of Livestock and Human Diseases Vector Control, Tropical Pesticides Research Institute, Ngaramtoni, Off Nairobi Road, PO Box 3024, Arusha, Tanzania. ${ }^{4}$ School of Forestry and Resource Conservation, National Taiwan University, No. 1, Sec.4, Roosevelt Road, Taipei 106, Taiwan.

${ }^{5}$ Department of Medical Parasitology and Entomology, Catholic University of Health and Allied Sciences, PO Box 1464, Mwanza, Tanzania.

Received: 21 February 2014 Accepted: 28 April 2014

Published: 2 May 2014

\section{References}

1. Aizoun N, Aikpon R, Gnanguenon V, Oussou O, Agossa F, Padonou G, Akogbeto M: Status of organophosphate and carbamate resistance in Anopheles gambiae sensu lato from the south and north Benin, West Africa. Parasit Vectors 2013, 6:274

2. Vannini L, Reed T, Willis J: Temporal and spatial expression of cuticular proteins of Anopheles gambiae implicated in insecticide resistance or differentiation of $\mathrm{M} / \mathrm{S}$ incipient species. Parasit Vectors 2014, 7:24.

3. Jones C, Haji K, Khatib B, Bagi J, Mcha J, Devine G, Daley M, Kabula B, Ali A Majambere $\mathrm{S}$, Ranson $\mathrm{H}$ : The dynamics of pyrethroid resistance in Anopheles arabiensis from Zanzibar and an assessment of the underlying genetic basis. Parasit Vectors 2013, 6:343.

4. Stenhouse S, Plernsub S, Yanola J, Lumjuan N, Dantrakool A, Choochote W, Somboon P: Detection of the V1016G mutation in the voltage-gated sodium channel gene of aedes aegypti (Diptera: culicidae) by allele-specific PCR assay, and its distribution and effect on deltamethrin resistance in Thailand. Parasit Vectors 2013, 6:253.

5. Nardini L, Christian R, Coetzer N, Koekemoer L: DDT and pyrethroid resistance in Anopheles arabiensis from South Africa. Parasit Vectors 2013, $6: 229$

6. Hemingway J: Malaria taking aim at mosquitoes. Nature 2004, 430:936

7. Hemingway J, Field L, Vontas J: An overview of insecticide resistance. Science 2002, 298:96-97.

8. Stefanazzi N, Stadler T, Ferrero A: Composition and toxic, repellent and feeding deterrent activity of essential oils against the storedgrain pests Tribolium castaneum (Coleoptera: tenebrionidae) and Sitophilus oryzae (Coleoptera: curculionidae). Pest Manag Sci 2011, 67:639-646

9. Khani A, Asghari J: Insecticide activity of essential oils of mentha longifolia, pulicaria gnaphalodes and achillea wilhelmsii against two stored product pests, the flour beetle, tribolium castaneum, and the cowpea weevil, callosobruchus maculatus. J Insect Sci 2012, 12:1-10.

10. Jembere B, Obeng-Ofori D, Hassanali A, Nyamasyo GNN: Products derived from the leaves of Ocimum kilimandscharicum (Labiatae) as post-harvest grain protectants against the infestation of three major stored product insect pests. Bull Entomol Res 1995, 85:361-367.

11. George D, Finn R, Graham K, Sparagano O: Present and future potential of plant-derived products to control arthropods of veterinary and medical significance. Parasit Vectors 2014, 7:28

12. Karunamoorthi K: Plant-based insect repellents: is that a sustainable option to curb the malaria burden in Africa? Med Aromat Plants 2012, $1: 2$

13. Karunamoorthi K, Ramanujam S, Rathinasamy R: Evaluation of leaf extracts of Vitex negundo L. (Family: verbenaceae) against larvae of Culex 
tritaeniorhynchus and repellent activity on adult vector mosquitoes. Parasitol Res 2008, 103:545-550.

14. Dugassa S, Medhin G, Balkew M, Seyoum A, Gebre-Michael T: Field investigation on the repellent activity of some aromatic plants by traditional means against Anopheles arabiensis and An. pharoensis (Diptera: culicidae) around Koka, central Ethiopia. Acta Trop 2009, 112:38-42.

15. Seyoum A, Killeen GF, Kabiru EW, Knols BGJ, Hassanali A: Field efficacy of thermally expelled or live potted repellent plants against African malaria vectors in western Kenya. Trop Med Int Health 2003, 8:1005-1011.

16. Mng'ong'o FC, Sambali JJ, Sabas E, Rubanga J, Magoma J, Ntamatungiro AJ, Turner EL, Nyogea D, Ensink JHJ, Moore SJ: Repellent plants provide affordable natural screening to prevent mosquito house entry in tropical rural settings-results from a pilot efficacy study. PLOS ONE 2011, 6:e25927.

17. Kweka E, Mosha F, Lowassa A, Mahande A, Mahande M, Massenga C, Tenu F, Lyatuu E, Mboya M, Temu E: Longitudinal evaluation of ocimum and other plants effects on the feeding behavioral response of mosquitoes (Diptera: culicidae) in the field in Tanzania. Parasit Vectors 2008, 1:42.

18. Odalo JO, Omolo MO, Malebo H, Angira J, Njeru PM, Ndiege IO, Hassanali A: Repellency of essential oils of some plants from the Kenyan coast against Anopheles gambiae. Acta Trop 2005, 95:210-218.

19. Gu H-J, Cheng S-S, Lin C-Y, Huang C-G, Chen W-J, Chang S-T: Repellency of essential oils of cryptomeria japonica (Pinaceae) against adults of the mosquitoes aedes aegypti and aedes albopictus (Diptera:culicidae). J Agric Food Chem 2009, 57:11127-11133.

20. Jayaprakasha GK, Jagan Mohan Rao L, Sakariah KK: Volatile constituents from Cinnamomum zeylanicum fruit stalks and their antioxidant activities. J Agric Food Chem 2003, 51:4344-4348.

21. Chang S-T, Chen P-F, Chang S-C: Antibacterial activity of leaf essential oils and their constituents from cinnamomum osmophloeum. J Ethnopharmacol 2001, 77:123-127.

22. Reichling J, Schnitzler P, Suschke U, Saller R: Essential oils of aromatic plants with antibacterial, antifungal, antiviral, and cytotoxic propertiesan overview. Forsch Komplementmed 2009, 16:79-90

23. Kalemba D, Kunicka A: Antibacterial and antifungal properties of essential oils. Curr Med Chem 2003, 10:813-829.

24. Cheng S-S, Liu J-Y, Huang C-G, Hsui Y-R, Chen W-J, Chang S-T: Insecticidal activities of leaf essential oils from cinnamomum osmophloeum against three mosquito species. Biores Technol 2009, 100:457-464.

25. Cheng S-S, Liu J-Y, Tsai K-H, Chen W-J, Chang S-T: Chemical composition and mosquito larvicidal activity of essential oils from leaves of different cinnamomum osmophloeum provenances. J Agric Food Chem 2004, 52:4395-4400.

26. Cheng S-S, Lin H-Y, Chang S-T: Chemical composition and antifungal activity of essential oils from different tissues of Japanese cedar (Cryptomeria japonica). J Agric Food Chem 2005, 53:614-619.

27. Sparkman OD: Identification of essential oil components by gas chromatography/quadrupole mass spectroscopy Robert P Adams. J Am Soc Mass Spectrom 2005, 16:1902-1903.

28. World Health Organization: Guidelines for laboratory and field testing of mosquito larvicides. 2005. http://whalibdoc.who.int/hq/2005/WHO_CDS WHOPES_GCDPP_2005.13.pdf.

29. Kweka E, Nyindo M, Mosha F, Silva A: Insecticidal activity of the essential oil from fruits and seeds of Schinus terebinthifolia Raddi against African malaria vectors. Parasit Vectors 2011, 4:129.

30. Abbott WS: A method of computing the effectiveness of an insecticide: 1925. J Am Mosa Control Assoc 1987, 3:302-303.

31. Finney DJ: Probit analysis. 3rd edition. New York, Ny 10022,32 E. 57th St: Cambridge University Press; 1971

32. Bossou AD, Mangelinckx S, Yedomonhan H, Boko PM, Akogbeto MC, De Kimpe N, Avlessi F, Sohounhloue DC: Chemical composition and insecticidal activity of plant essential oils from Benin against Anopheles gambiae (Giles). Parasit Vectors 2013, 6:337.

33. Tren R, Roberts D: DDT and malaria prevention. Environ Health Perspect 2010, 118:A14-A15. author reply A15-16.

34. Ghosh A, Chowdhury N, Chandra G: Laboratory evaluation of a phytosteroid compound of mature leaves of Day Jasmine (Solanaceae: solanales) against larvae of Culex quinquefasciatus (Diptera: culicidae) and nontarget organisms. Parasitol Res 2008, 103:271-277.
35. Marina C, Bond J, Munoz J, Valle J, Novelo-Gutierrez R, Williams T: Efficacy and non-target impact of spinosad, Bti and temephos larvicides for control of Anopheles spp. in an endemic malaria region of southern Mexico. Parasit Vectors 2014, 7:55.

36. Killeen GF, Fillinger U, Kiche I, Gouagna LC, BG K: Eradication of Anopheles gambiae from Brazil: lessons for malaria control in Africa? Lancet Infect Dis 2002, 2:618-627.

doi:10.1186/1756-3305-7-209

Cite this article as: Mdoe et al:: Activity of Cinnamomum osmophloeum leaf essential oil against Anopheles gambiae s.s. Parasites \& Vectors 2014 7:209

\section{Submit your next manuscript to BioMed Central and take full advantage of:}

- Convenient online submission

- Thorough peer review

- No space constraints or color figure charges

- Immediate publication on acceptance

- Inclusion in PubMed, CAS, Scopus and Google Scholar

- Research which is freely available for redistribution
C Biomed Central 